OPEN ACCESS

Edited by:

Ada Funaro,

University of Turin, Italy

Reviewed by:

Santina Bruzzone

University of Genoa, Italy

Jaime Sancho,

Instituto de Parasitología y

Biomedicina López-Neyra (IPBLN),

Spain

*Correspondence:

Alla B. Salmina

allasalmina@mail.ru

Specialty section:

This article was submitted to

Molecular Innate Immunity,

a section of the journal

Frontiers in Immunology

Received: 20 July 2020

Accepted: 12 October 2020

Published: 10 November 2020

Citation:

Lopatina OL, Komleva YK,

Malinovskaya NA, Panina YA, Morgun AV and Salmina AB (2020)

CD157 and Brain Immune System in

(Patho)physiological Conditions:

Focus on Brain Plasticity.

Front. Immunol. 11:585294.

doi: 10.3389/fimmu.2020.585294

\section{CD157 and Brain Immune System in (Patho)physiological Conditions: Focus on Brain Plasticity}

\author{
Olga L. Lopatina ${ }^{1,2,3,4}$, Yulia K. Komleva ${ }^{1,2}$, Natalia A. Malinovskaya ${ }^{1,2}$, Yulia A. Panina ${ }^{1,2}$, \\ Andrey V. Morgun ${ }^{2}$ and Alla B. Salmina ${ }^{1,2 *}$ \\ ${ }^{1}$ Department of Biochemistry, Medical, Pharmaceutical, and Toxicological Chemistry, Krasnoyarsk State Medical University \\ named after Prof. V.F. Voino-Yasenetsky, Krasnoyarsk, Russia, ${ }^{2}$ Research Institute of Molecular Medicine and \\ Pathobiochemistry, Krasnoyarsk State Medical University named after Prof. V.F. Voino-Yasenetsky, Krasnoyarsk, Russia, \\ ${ }^{3}$ Laboratory for Social Brain Studies, Research Institute of Molecular Medicine and Pathobiochemistry, Krasnoyarsk State \\ Medical University named after Prof. V.F. Voino-Yasenetsky, Krasnoyarsk, Russia, ${ }^{4}$ Department of Biophysics, Siberian \\ Federal University, Krasnoyarsk, Russia
}

Ectoenzyme and receptor BST-1/CD157 has been considered as a key molecule involved in the regulation of functional activity of cells in various tissues and organs. It is commonly accepted that CD157 catalyzes NAD+ hydrolysis and acts as a component of integrin adhesion receptor complex. Such properties are important for the regulatory role of CD157 in neuronal and glial cells: in addition to recently discovered role in the regulation of emotions, motor functions, and social behavior, CD157 might serve as an important component of innate immune reactions in the central nervous system. Activation of innate immune system in the brain occurs in response to infectious agents as well as in brain injury and neurodegeneration. As an example, in microglial cells, association of CD157 with CD11b/CD18 complex drives reactive gliosis and neuroinflammation evident in brain ischemia, chronic neurodegeneration, and aging. There are various non-substrate ligands of CD157 belonging to the family of extracellular matrix proteins (fibronectin, collagen I, finbrinogen, and laminin) whose activity is required for controlling cell adhesion and migration. Therefore, CD157 could control structural and functional integrity of the bloodbrain barrier and barriergenesis. On the other hand, contribution of CD157 to the regulation of brain development is rather possible since in the embryonic brain, CD157 expression is very high, whereas in the adult brain, CD157 is expressed on neural stem cells and, presumably, is involved in the neurogenesis. Besides, CD157 could mediate astrocytes' action on neural stem and progenitor cells within neurogenic niches. In this review we will summarize how CD157 may affect brain plasticity acting as a molecule at the crossroad of neurogenesis, cerebral angiogenesis, and immune regulation.

Keywords: CD157, immune system, brain plasticity, social brain, brain development 


\section{INTRODUCTION}

$\mathrm{NAD}+$ metabolism is recognized as an important factor contributing to numerous metabolic events and intercellular communications. Several NAD+-consuming enzymes have been discovered in recent 3 decades. Particularly, CD38 and CD157 represent the pair of ectoenzymes involved in the catalytic degradation of $\mathrm{NAD}+$ leading to production of second messengers with pivotal biological effects (i.e., control of $\mathrm{Ca} 2+$ release from intracellular stores, regulation of cell movement, etc.) (1-3).

CD157 is well known as bone marrow stromal cell antigen-1 (BST-1) (4), that was first isolated from a bone marrow stromal cells (5), and the BST1 gene was identified by gene cloning as CD157 (6). CD157/BST-1 together with CD38 belong to the NADase/ADP-ribosyl cyclase family, catalyzing the conversion of $\mathrm{NAD}^{+}$and $\mathrm{NADP}^{+}$to cyclic ADP-ribose (cADPR) and nicotinic acid adenine dinucleotide phosphate (NAADP) (4, 715). CD157/BST-1 exhibits the same dualism of properties as CD38 like receptor and enzyme activity in leukocytes and ovarian cancer cells $(16,17)$, bone marrow stromal cells $(18)$, myeloid cells $(6,19,20)$, and netrophils and hematopoietic stem cells $(14,18,21-23)$.

Interesting, the ADP-ribosyl cyclase activity of CD157 is not so much strong like that one of CD38 including brain. However, it is not clear whether CD157 has other enzyme activities, such as NAD glycohydrolase or NAD base exchange activities. The product of base exchange is nicotinic acid adenine dinucleotide phosphate (NAADP). NAADP also has $\mathrm{Ca}^{2+}$ mobilization activity from different $\mathrm{Ca}^{2+}$ pools. $\mathrm{CD} 38$ initiates calcium mobilization through two products: NAADP and cADPR, but CD157 uses only cADPR pathway $(11,24,25)$. Perhaps, sibling rivalry between $\mathrm{CD} 157$ and $\mathrm{CD} 38$ has become more exiting (26).

From the point of the social brain the role of $\mathrm{CD} 38$ in oxytocin (OT) secretion into the brain has been established: CD38 mediates cADPR production, TRMP2 and ERK1/2 activation, $\mathrm{Ca}^{2+}$-mobilization, and OT release. Additionally, CD38 is involved in OT release by activating molecular cascades of OT autoregulation (27-30). In contrast, CD157 binds with the serotonin transporter and integrin $\beta$ and invokes multiple circuits to control anxiety- and depressionlike behaviors $(24,31,32)$. CD157 plays a role in cADPR-induced OT release, which may not be same to that of CD38. The deficiency of CD157 leads to aberrant behaviors, such as increased anxiety.

Interestingly, despite the important role of $\mathrm{CD} 157$ in the immune system (33-35), the CD157/BST1 gene has been identified as a risk factor for neurodegeneration (36), particularly in Parkinson's disease (PD) (37-48). A new role for CD157 was also found in stem cells when CD157 induces catalysis of cADPR in Paneth cells, which promote self-renewal of stem cells in the intestines in mice on a low-calorie diet (49) and CD157 is responsible for the proliferation of stem and progenitor cells in the lungs (50). The role of CD157 in the regulation of brain activity and plasticity is very intriguing and needs in further evaluation.

\section{CD157 AND BRAIN IMMUNE RESPONSE}

CD157 is widely expressed in the brain. CD157 immunoreactivity was detected in the cytoplasm or at the cell surface of many but not all nestin-positive cells in the ventricular and subventricular zones beside the third ventricle $(1,24)$. In the nervous system, CD157 may play a role in neuronal migration during neural stem cell (NSC) proliferation and neurogenesis. It has been shown that $\mathrm{CD} 157$ binds with members of the integrin family $(24,51)$.

It is also interesting that CD157 is highly expressed in immune cells that are very active in a case of local brain immune response and neuroinflammation. Indeed, microglia cells demonstrate co-expression of CD157 with CD11b and CD18 in experimental Parkinson's disease in rats (52).

$\mathrm{CD} 11 \mathrm{~b}$ and $\mathrm{CD} 18$ are molecules involved in the regulation of (micro)glial activity being the beta 2-integrin receptor, or complement 3 receptor (Mac-1), or receptor for doublestranded RNA (i.e., of viral origin) (53-55).

CD157 may serve as a part of this complex (56) where its role is in the regulation of leukocyte functional activity. Since activity of Mac-1 as a receptor for extracellular double-stranded RNA (dsRNA), CD157 may be important for sensing dsRNA by glial cells in neuroinflammation as we have suggested before (57). In brain, expression of $\mathrm{CD} 11 \mathrm{~b} / \mathrm{CD} 18$ receptor complex is evident in either astroglial or microglial cells. Stimulation of Mac-1 results in the activation of tall-like receptor-3 (TLR3) and triggers TLR3-independent oxidative inflammatory signaling. Moreover, coordinated activity of Mac-1 and the receptor for advanced glycation end products (RAGE) is involved in development of inflammation, i.e., in neurodegeneration (52, 58). CD157, CD11b, and CD18 co-expression has been detected in microglial cells in experimental Parkinson's disease in rats (52). It is well-known that activation of TLR3 in blood brain barrier (BBB) cells leads to BBB breakdown, activation of innate immune response and inflammation in the brain affected by degeneration or ischemia (59). Also, TLR3-coupled cell signaling is involved in the disruption of $\mathrm{BBB}$ evident in immunologically induced chronic fatigue syndrome (60) when inflammationinduced changes in neuron-glial interactions result in the activation of local immune response and cytokines-driven BBB breakdown. Involvement of viral dsRNA in the pathogenesis of chronic fatigue syndrome that was confirmed in the fatigue model induced by dsRNA poly (I:C) (61), and critical role of $\mathrm{CD} 11 \mathrm{~b} / \mathrm{CD} 18$ complex in the recognition of dsRNA in immune cells (55) provide novel insights on the activity of Mac-1 complex and associated molecules (including CD157). Thus, it is reasonable to speculate that physical and functional association of $\mathrm{CD} 157$ with $\mathrm{CD} 11 \mathrm{~b} / \mathrm{CD} 18$ could affect TLR3-dependent and independent signaling, thereby resulting in development of local inflammation caused by the release of PAMPs and DAMPs to the extracellular space, or by the presence of viral dsRNA in the brain tissue.

Therefore, it is not surprising that ATP-mediated purinergic signaling via $\mathrm{P} 2 \mathrm{X} 7$ receptors induces expression of $\mathrm{CD} 157$ in brain microvessel endothelial cells (BMECs) in mice (62), thereby providing a basis for the transmigration of activated peripheral immune cells through the blood-brain barrier into 
brain tissue. Taking into the consideration the well-established role of CD157 in the regulation of leukocytes movement across the endothelial layer (34), one could propose that integrinmediated control of the blood-brain barrier integrity might be partly provided by CD157 expressed on brain microvessel endothelial cells. In addition to molecules involved into the control of transendothelial leukocytes migration (CD31, cadherins, JAMs etc.), CD157 expressed by neutrophils and endothelial cells was found to be involved into the regulation of cell adhesion during chemotaxis and transmigration at imflammatory loci (51). This could suggest new clues to the pathogenesis of immune response-associated blood-brain barrier breakdown and progression of neuroinflammation due to excessive migration of peripheral blood leukocytes into the brain tissue at the sites of compromised blood-brain barrier permeability. Moreover, it should be noted, that NAD+ metabolism is of great importance for maintaining metabolic activity of brain microvessel endothelial cells and BBB integrity (63); therefore, catalytic activity of CD157 expressed in endothelial cells might be required for the activation of BMECs seen in brain injury. Recent data on the role of NAD+ depletion in endothelial cells accompanied aging and degeneration further support such assumption (64); however, whether or not it relates to the activation of CD157 remains to be evaluated.

\section{CD157 AND SOCIAL BRAIN}

Systemic and local inflammation often associates with behavioral and cognitive deficits (65). Recent data suggest that it might result in prominent alterations in social behavior (66). Moreover, aberrant immune response has been reported in various models of chronic neurodegeneration, autism spectrum disorder (ASD), and schizophrenia $(66,67)$. As an example, maternal immune activation caused by poly(I:C) drives development of autism-like phenotype in the offspring, demonstrating dependence on purinergic receptors (P2X7) expression in the brain (68). So, the question arises whether CD157 could contribute to the immunity-mediated control of social behavior.

Recently, it was found that the CD157/BST1 gene polymorphisms are associated with some neurological diseases, including ASD (69, 70 ), which provoked to work with animals with a deletion of the CD157/BST1 gene and to evaluate the possibility of using CD157 $7^{-1-}$ mice as models of ASD or autistic-like behavior with a social deficit in the absence of motor dysfunctions (especially in childhood and early adolescent).

Social interaction and communication is the most vulnerable behavioral trait in children with $\operatorname{ASD}(71,72)$. Communicative skills are formed in the early period of life and require the use of language as the main tool for the two-way transmission of information. At the same time, mice are social animals with their own communication system with ultrasonic vocalization (USV) in various contexts (73-76). Mouse USV are a whole complex with various qualitative (form, frequency, duration, intensity of sounds, etc.) and quantitative (number of USV produced) $(77,78)$ characteristics; which, of course, is not a human language.

It was shown that deletion of the $C d 157$ gene in mice causes a deviation in the development of the production of ultrasonic vocalization during lactation (32). Young mice, removed from the nest and isolated from the mother, vocalize with a communicative orientation, which correlates with social contacts and research behavior of rodents (79). Neonatal USV can be a guide in understanding remote adult anxiety profiles $(78,80)$. However, the decrease in vocalization after PND 3, which we observed in $\mathrm{CD}_{157^{-/}}$mice, can be considered as a delayed violation of communication skills. This may be partially associated with the previously noted autistic (anxious and restless) similar behavior in $\mathrm{CD} 157^{-/-}$mice (32).

The structure and organization of the language is actively studied in patients with ASD. Pragmatics is the most "socially motivated" and consistently devalued domain for ASD because it requires an understanding of the language and its correct interpretation during social interactions (72). The language of instruction is tied to mechanical and motor functions, since there is a connection between motor skills and speech function. Atypical motor movements were observed with various phenotypes of ASD (81). Poor vocabulary and its active use in patients with ASD seems to be associated with reduced motivation for communication (82). The registration of USV produced by mouse cubs during social isolation can be distinguished as an index of social motivation of cubs to stimulate parental care and as a marker of early communication deficits in ASD models in mice in anticipation of other, long-term, changes $(83,84)$. Such scientific studies demonstrate the potential positive effect of introducing oxytocin on increasing motivation for targeted behavior (85) and promoting fundamental psychophysiological functions in the implementation of social behavior, which in turn contributes to social activity (86). Administration of exogenous oxytocin can improve brain function in children with ASD (87). Taking into account all the data we obtained and previously published scientific studies, we assume that the introduction of oxytocin activates the potential flexibility of neuron functions, which does not directly stimulate indirect motivation and, possibly, helps to develop vocabulary and increase vocabulary.

Actually, this is the first study demonstrating the relationship of CD157 with early postnatal development and communicative abilities (which can be restored by introducing exogenous oxytocin). The CD157 gene can be a candidate gene and a risk factor for the development of states of anxiety and social avoidance (social fear). This data can make a great contribution to the study of molecular mechanisms that underlie disturbances in social interactions, in particular, communicative deficits in ASD. However, one study demonstrates that single-nucleotide polymorphisms (SNPs) are rs28532698 and rs4301112 in CD157not predictors of childhood ASD in the Chinese Han population (88), but CD157 sequence variation predicts scores on the Friendship questionnaire (89).

Results of experiments show that $\mathrm{CD} 157^{-/-}$young adult male mice displayed anxiety-related behaviors for the novel 
environment; exhibited anxiety for non-social and/or social novel targets $(31,90)$. Weak sociability with novel target mice and social avoidance for target males were recover with oxytocin application (31, 32). A new oxytocin analog, lipo-oxytocin-1 (LOT-1), similar to OT, rescued anxiety-like behavior and social avoidance in CD157 knockout mice (91).

In addition, $\mathrm{CD} 157^{-/}$mice displayed depression-like behaviors and response well for antidepressant treatment (90). Significant differences in the activity of ADP-ribosyl cyclase in the hypothalamus and the pituitary gland between the two genotypes were not observed. Measurement of the oxytocin level in blood plasma showed that the concentration of oxytocin in $\mathrm{CD} 157^{-/-}$mice was significantly lower than in mice of the control group (31) (Figure 1). It was interesting to analyze how these behavioral impairments in $\mathrm{CD} 157^{-/-}$mice could reflect impairment of the amygdala $(31,92,93)$ and what is the role of CD157 in adult neurogenesis. However, there is no direct evidence that CD157 plays a role in neuronal migration during neurogenesis, although CD157 binds integrins in human monocytes and plays a role in neutrophil migration $(31,32)$.

In sum, CD157 directly or indirectly affects the central axonal release of OXT, which proves the observed change in the oxytocin system (plasma concentration) and the compensatory effect of oxytocin on the behavior of $\mathrm{CD} 157^{-/-}$mice. Targeted modulation of CD157 expression in the brain could be considered as an approach to restore behavioral deficits seen in brain disorders associated with impaired social behavior and stress tolerance.

\section{CD157 AND NEUROPLASTICITY}

Subgranular zone (SGZ) of hippocampus and subventricular zone (SVZ) are the main areas of the brain where neurogenesis occurs in adulthood due to presence of neurogenic niches with the optimal microenvironment required for maintenance of populations of NSCs, proliferation of neural progenitor cells (NPCs), further differentiation and migration of cells of neuronal and glial lineages $(94,95)$.

Deletion of the $C d 157$ gene is associated with behavioral characteristic of a number of neurodevelopment and neurodegenerative diseases. Violations of socialization, social recognition, and anxiety are associated with learning and memory processes, while autism is associated with impaired synaptogenesis. Moreover, deletion of the $C d 157$ gene causes a decrease in the proliferation of neuronal progenitor cells in the SGZ, which can be seen from the significant decrease in the expression of the Nestin marker in the SGZ of the dentate gyrus of $\mathrm{CD} 157^{-/-}$mice compared with wild-type C57BL/6 mice (1.43 \pm $2.36 \%$ and $8.0 \pm 2.41 \%$, respectively, $\mathrm{P}=0.0039$ ). A tendency toward a decrease in the expression of the marker of neuroblasts (MAP2) in the SGZ of CD157 $7^{-/-}$mice $(12.64 \pm 4.44 \%)$ compared with the control group $(25.12 \pm 5.77 \%, \mathrm{P}=0.0410)$. However, no differences were found in the expression of the marker for immature neurons (doublecortin, DCX) in the experimental and control groups, which indicates that CD157 does not control the number of immature neurons.

There was statistically significant decrease of the expression of the postsynaptic density marker PSD95 in the SGZ of the dentate

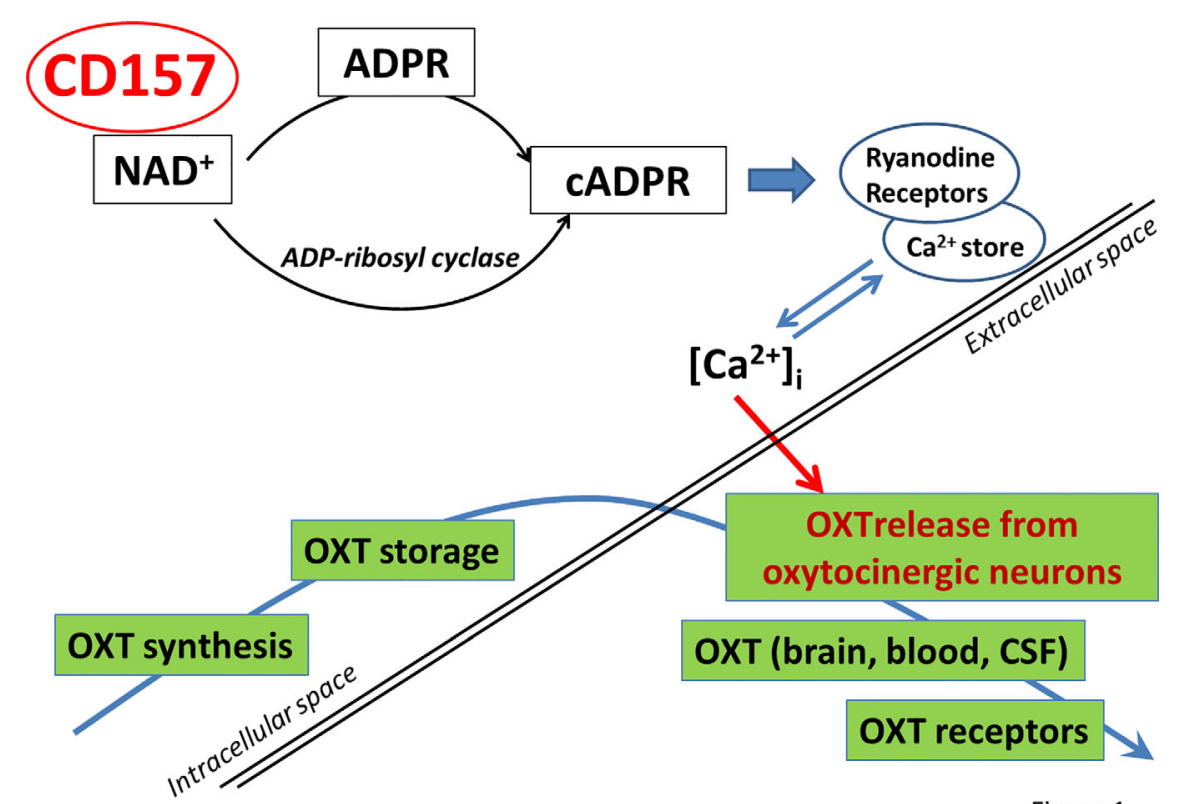

Figure 1

FIGURE 1 | Model illustrating the potential role of CD157 in oxytocin release. CD157 catalyzes NAD+ hydrolysis and synthesis of CADPR, then cADPR acts at Ryanodine receptors expressed in intracellular $\mathrm{Ca}^{2+}$ stores to initiate $\left[\mathrm{Ca}^{2+}\right]$ irelease to cytosole. As a result, OXT is secreted from the cell into the blood and brain tissue. ADPR, ADP-ribose; cADPR, cyclic ADP-ribose; OXT, oxytocin. 
gyrus in $\mathrm{CD} 157^{-/-}$mice $(18.79 \pm 1.88 \%)$ was revealed compared with the control ( $40.51 \pm 0.13 \%, P=0.0089$, Figure 2$)$. We found no difference in Staufen expression (an RNA-binding protein involved in the localization and transport of dendritic mRNA; a marker of neuronal RNA granules) in the dentate gyrus of the hippocampus of $\mathrm{CD} 157^{-/-}$mice and wild-type C57BL/6 mice $(67.07 \pm 4.28 \%$ and $69.19 \pm 5.67 \%$, respectively, $\mathrm{P}=0.7834)$ (Figure 2). But we detected a tendency to a decrease in the expression of MAP2 (associated with protein microtubules) in the same brain area in $\mathrm{CD} 157^{-/-}$mice compared to the control group (Figure 2). Deletion of the Cd157 gene is statistically significantly associated with decreased expression of Synaptophysin in the studied brain area (Figure 2). These results demonstrate that absence of CD157 expression suppresses synaptogenesis in the hippocampus.

Olfactory bulbs in rodents serve as platform for the integration of newly-formed neurons in neuronal circuits throughout the life being in close functional connection with the SVZ (96). We found significant increase in the expression of CD157 by microglial cells during neurodegeneration in olfactory bulbs $(4.12 \pm 1.52 \%)$ compared with the control group of shamoperated mice $(0.72 \pm 0.38 \%, \mathrm{P}=0.027)$. Also, a statistically significant increase of CD157 expression was recorded in astrocytes expressing GFAP in neurodegeneration group $(5.74 \pm$ $1.45 \%)$ compared with the sham-operated control $(1.03 \pm 0.39 \%$, $\mathrm{P}=0.05)$. In $\mathrm{S} 100 \beta+$ astrocytes, the expression of CD157 demonstrated tendency to increase ( $P=0.086$, Table 1). Thus, progression of neurodegeneration is accompanied by an increase in the expression of CD157 in microglia cells in rodent olfactory bulbs, thereby suggesting a role of activated microglial cells in the control of newly-formed neurons integration into pre-existing circuits. In microglial cell, similar to immune cells, CD157 is responsible for cytoskeletal rearrangement associated with cell activation and migration and can form a functional complex

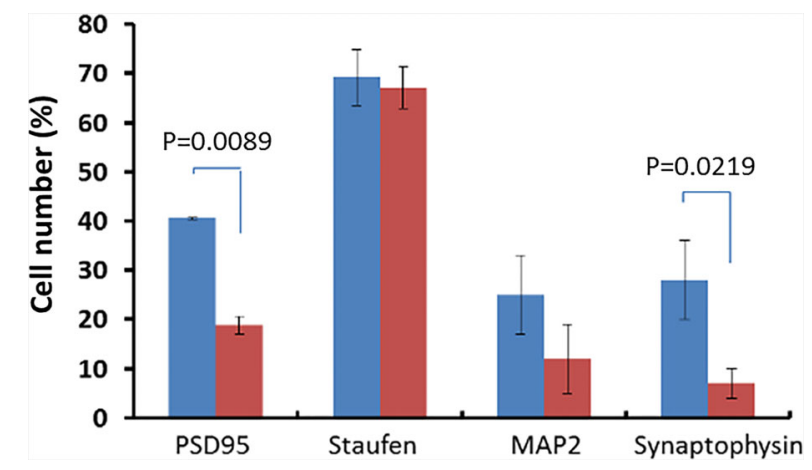

FIGURE 2 | Deficiency of synaptogenesis under deletion of the Cd157 gene. Expression of synaptogenesis markers (PSD95, Staufen, MAP2,

Synaptophysin) in the subgranular zone of the dentate gyrus of the hippocampus in $\mathrm{CD}_{157^{-/}}$mice (red marker) and in the control group of mice $\left(\mathrm{CD} 157^{+/+}\right.$mice, blue marker). The number of positive cells is presented as a percentage of the total number of cells in the field of view (five visual fields were evaluated). Two-way ANOVA (genotype effect, $F(1.32)=36.26, P=$ 0.0007) followed by Bonferroni's post hoc test.
TABLE 1 | The number of CD157+ microglia and astrocytes (\%) in olfactory bulbs in control animals and with neurodegeneration.

\begin{tabular}{lccc}
\hline Groups & \multicolumn{3}{c}{ Cell type } \\
\cline { 2 - 4 } & $\begin{array}{c}\text { Microglia (MAC-1, } \\
\text { CD18/CD11b) }\end{array}$ & $\begin{array}{c}\text { Astrocyte } \\
\text { (GFAP+) }\end{array}$ & $\begin{array}{c}\text { Astrocytes } \\
\text { (S100 } \beta+)\end{array}$ \\
\hline $\begin{array}{l}\text { Neurodegeneration }(\beta- \\
\text { amyloid injection) }\end{array}$ & $4.12 \pm 1.52$ & $5.74 \pm 1.45$ & $2.45 \pm 1.48$ \\
$\begin{array}{l}\text { Control (sham-operated) } \\
P\end{array}$ & $0.72 \pm 0.38$ & $1.03 \pm 0.39$ & $0.46 \pm 0.08$ \\
& 0.027 & 0.05 & 0.086 \\
\hline
\end{tabular}

Animals, $n=5$ in every group; slices, $n=5$ from every brain; field of view, $n=5$ from every slice.

with the CD11b/CD18, thus contributing to cell adhesion (97). Meta-analysis suggests that the rs11931532 and rs4698412 in CD157, but not rs11724635 might be risk factors for Parkinson's disease in Asian populations (98).

In sum, it is clear that CD157 is involved in the formation of immature neurons and in the proliferation of neuronal cells. In this case CD157 does not affect the number of immature neurons. However, the absence of CD157 negatively affects the processes of synaptogenesis, whereas progression of neurodegeneration is accompanied by CD157 overexpression in brain cells.

Functional association of CD157 and CD200 on stem cells (99) may provide novel role of CD157 in the regulation of stem cells development in neurogenic niches established in a close vicinity to the sites of hyperpermeable BBB (100). Recently, CD157 was confirmed as a marker of tissue-resident vascular endothelial stem cells (VESCs) in large arteries and veins of numerous mouse organs (101), thereby supporting new idea on its role in the immune-controlled regulation of angiogenesis and vascular remodeling (99). It was proposed that CD200+ CD157+ endothelial cells (ECs) are self-renewing stem cells contributing to angiogenesis and vasculogenesis by supplying terminally differentiating ECs through a stage of CD200+CD157- endothelial progenitors (102). Moreover, therapeutic application of CD200+CD157+ progenitors aimed to restore angiogenic potential in the affected tissues could be proposed (102). The same approach might be applied for the establishment of new BBB in vitro models, particularly those reflecting aberrant barrier integrity evident in neuroinflammation and neurodgeneration (103). In sum, CD157-immunopositive endothelial progenitor cells may display great regenerative potential in tissues, including brain (101); however, nothing is known about this cell pool in the context of brain microvessel development in embryonic or adult stages, and it requires further assessment.

\section{CONCLUSION}

CD157 is defined as a neuro-entero-immunological regulator. The Cd157 gene can be a candidate gene and a risk factor for the development of states of anxiety and social avoidance (social fear), and the CD $157^{-/-}$mice is a relevant model for the study of mental disorders and brain plasticity, including those characteristic of humans. In addition to recently discovered 


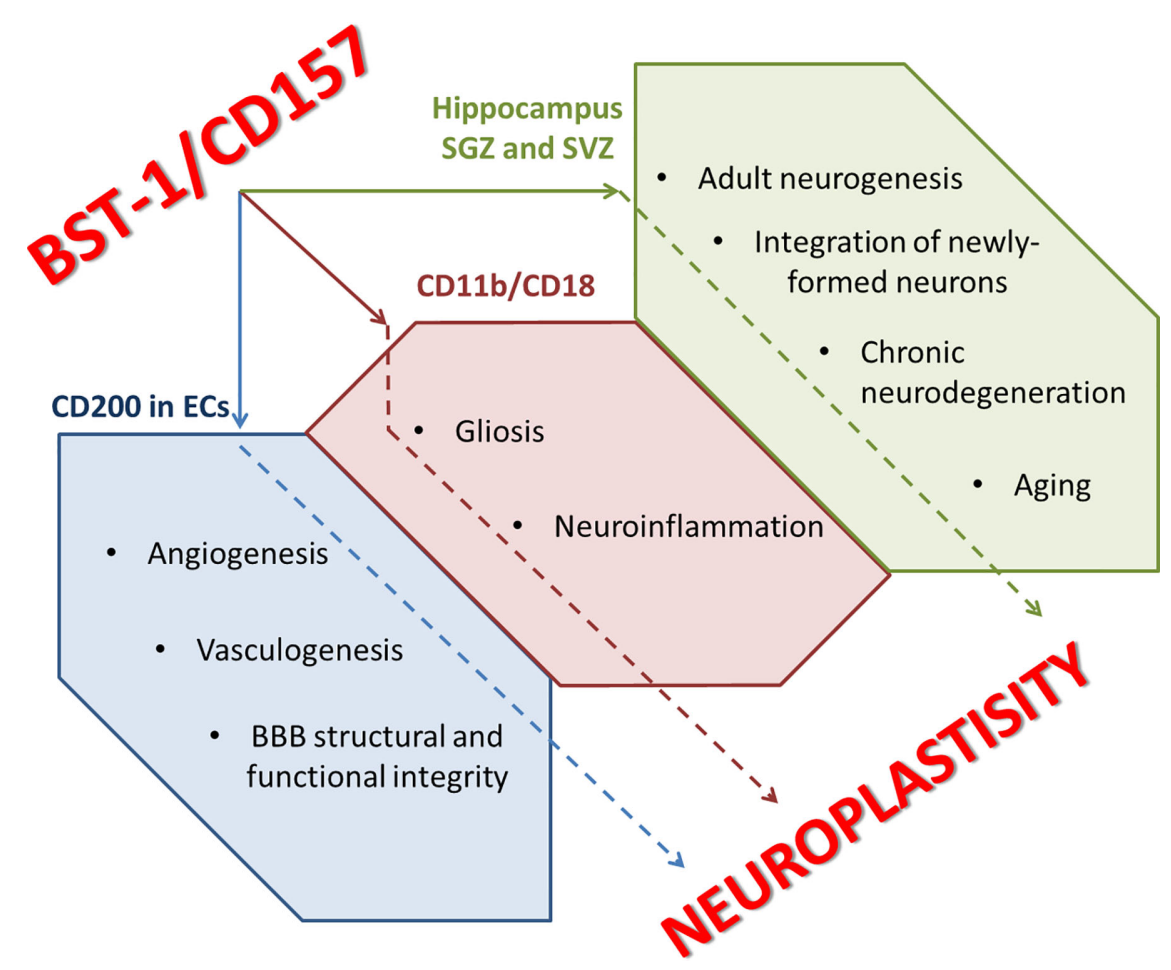

FIGURE 3 | CD157 and neuroplastisity. ECs, endothelial cells; SGZ, subgranular zone of hippocampus; SVZ, subventricular zone of hippocampus.

role in the regulation of emotions, motor functions and social behavior, CD157 might serve as an important component of innate immune reactions in the central nervous system. Involvement of CD157 to the regulation of brain development is rather possible since in the embryonic brain where CD157 expression is very high, whereas in the adult brain, CD157 is expressed on NSCs and surrounding glial cells, being, probably, involved in the regulation of adult neurogenesis and integration of newly-formed neurons into pre-existing circuits. Functional association of $\mathrm{CD} 157$ with $\mathrm{CD} 11 \mathrm{~b} / \mathrm{CD} 18$ complex may drive reactive gliosis and neuroinflammation evident in brain ischemia, chronic neurodegeneration, and aging. Coupling of CD157 to CD200 in endothelial cells may affect angiogenesis and vasculogenesis, whereas expression of $\mathrm{CD} 157$ on mature brain endothelial cells may contribute to controlling BBB structural and functional integrity (Figure 3). In sum, CD157 should be recognized as a target molecule for the therapy of brain disorders

\section{REFERENCES}

1. Pehar M, Harlan BA, Killoy KM, Vargas MR. Nicotinamide Adenine Dinucleotide Metabolism and Neurodegeneration. Antioxid Redox Signal (2018) 28:1652-68. doi: 10.1089/ars.2017.7145

2. Salmina AB, Morgun AV, Kuvacheva NV, Lopatina OL, Komleva YK, Malinovskaya NA, et al. Establishment of neurogenic microenvironment in the neurovascular unit: the connexin 43 story. Rev Neurosci (2014) 25(1):97111. doi: 10.1515/revneuro-2013-0044 associated with immune dysfunction, aberrant neuroplasticity, and neuroinflammation.

\section{AUTHOR CONTRIBUTIONS}

AS and OL conceived of the presented idea. YK, NM, YP, and AM worked on the table and figures. All authors contributed to the article and approved the submitted version.

\section{FUNDING}

The study is supported by the grant HШ-2547.2020.7 of the President of Russian Federation given to Russian Leading Research Teams. 
5. Kaisho T, Ishikawa J, Oritani K, Inazawa J, Tomizawa H, Muraoka O, et al. BST-1, a surface molecule of bone marrow stromal cell lines that facilitates pre-B-cell growth. Proc Natl Acad Sci (1994) 91:5325-9. doi: 10.1073/ pnas.91.12.5325

6. Itoh $\mathrm{M}$, Ishihara $\mathrm{K}$, Tomizawa $\mathrm{H}$, Tanaka $\mathrm{H}$, Kobune $\mathrm{Y}$, Ishikawa J, et al. Molecular Cloning of Murine BST-1 Having Homology with CD38 and Aplysia ADP-Ribosyl Cyclase. Biochem Biophys Res Commun (1994) 203:1309-17. doi: 10.1006/bbrc.1994.2325

7. Ferrero E, Saccucci F, Malavasi F. The human CD38 gene: polymorphism, CpG island, and linkage to the CD157 (BST-1) gene. Immunogenetics (1999) 49:597-604. doi: 10.1007/s002510050654

8. Guse AH. Second messenger function and the structure-activity relationship of cyclic adenosine diphosphoribose (cADPR). FEBS J (2005) 272:4590-7. doi: $10.1111 / j .1742-4658.2005 .04863 . x$

9. Hirata Y, Kimura N, Sato K, Ohsugi Y, Takasawa S, Okamoto H, et al. ADP ribosyl cyclase activity of a novel bone marrow stromal cell surface molecule, BST-1. FEBS Lett (1994) 356:244-8. doi: 10.1016/0014-5793(94)01279-2

10. Itoh M, Ishihara $\mathrm{K}$, Hiroi $\mathrm{T}$, Lee BO, Maeda $\mathrm{H}$, Iijima $\mathrm{H}$, et al. Deletion of bone marrow stromal cell antigen-1 (CD157) gene impaired systemic thymus independent- 2 antigen-induced IgG3 and mucosal TD antigenelicited IgA responses. J Immunol (1998) 161:3974-83.

11. Lee HC. Cyclic ADP-ribose and NAADP: fraternal twin messengers for calcium signaling. Sci China Life Sci (2011) 54:699-711. doi: 10.1007/s11427011-4197-3

12. Lee HC. Structure and Enzymatic Functions of Human CD38. Mol Med (2006) 12:317-23. doi: 10.2119/2006-00086.Lee

13. Lee HC. Physiological functions of cyclic ADP-ribose and NAADP as calcium messengers. Annu Rev Pharmacol Toxicol (2001) 41:317-45. doi: 10.1146/annurev.pharmtox.41.1.317

14. Malavasi F, Deaglio S, Ferrero E, Funaro A, Sancho J, Ausiello CM, et al. CD38 and CD157 as Receptors of the Immune System: A Bridge Between Innate and Adaptive Immunity. Mol Med (2006) 12:334-41. doi: 10.2119/ 2006-00094.Malavasi

15. Yamamoto-Katayama S, Ariyoshi M, Ishihara K, Hirano T, Jingami H, Morikawa K. Crystallographic studies on human BST-1/CD157 with ADPribosyl cyclase and NAD glycohydrolase activities. J Mol Biol (2002) 316:711-23. doi: 10.1006/jmbi.2001.5386

16. Morone S, Augeri S, Cuccioloni M, Mozzicafreddo M, Angeletti M, Lo Buono N, et al. Binding of CD157 Protein to Fibronectin Regulates Cell Adhesion and Spreading. J Biol Chem (2014) 289:15588-601. doi: 10.1074/ jbc.M113.535070

17. Morone S, Lo-Buono N, Parrotta R, Giacomino A, Nacci G, Brusco A, et al. Overexpression of CD157 Contributes to Epithelial Ovarian Cancer Progression by Promoting Mesenchymal Differentiation. PloS One (2012) 7:e43649. doi: 10.1371/journal.pone.0043649

18. K Mehta, F Malavasi eds. Human CD38 and related molecules. Basel: Karger (2000).

19. Muraoka O, Tanaka H, Itoh M, Ishihara K, Hirano T. Genomic structure of human BST-1. Immunol Lett (1996) 54:1-4. doi: 10.1016/S0165-2478(96) 02633-8

20. Okuyama Y, Ishihara K, Kimura N, Hirata Y, Sato K, Itoh M, et al. Human BST-1 Expressed on Myeloid Cells Functions as a Receptor Molecule. Biochem Biophys Res Commun (1996) 228:838-45. doi: 10.1006/bbrc. 1996.1741

21. Funaro A, Ortolan E, Ferranti B, Gargiulo L, Notaro R, Luzzatto L, et al. CD157 is an important mediator of neutrophil adhesion and migration. Blood (2004) 104:4269-78. doi: 10.1182/blood-2004-06-2129

22. Mouchiroud L, Houtkooper RH, Auwerx J. NAD+ metabolism: A therapeutic target for age-related metabolic disease. Crit Rev Biochem Mol Biol (2013) 48:397-408. doi: 10.3109/10409238.2013.789479

23. Podestà $\mathrm{M}$, Benvenuto F, Pitto A, Figari O, Bacigalupo A, Bruzzone $\mathrm{S}$, et al. Concentrative Uptake of Cyclic ADP-ribose Generated by BST-1 ${ }^{+}$Stroma Stimulates Proliferation of Human Hematopoietic Progenitors. J Biol Chem (2005) 280:5343-9. doi: 10.1074/jbc.M408085200

24. Higashida H, Liang M, Yoshihara T, Akther S, Fakhrul A, Stanislav C, et al. An immunohistochemical, enzymatic, and behavioral study of CD157/BST1 as a neuroregulator. BMC Neurosci (2017) 18:1-12. doi: 10.1186/s12868017-0350-7
25. Kim U-H. Multiple Enzymatic Activities of CD38 for $\mathrm{Ca}^{2+}$ Signaling Messengers. Messenger (2014) 3:6-14. doi: 10.1166/msr.2014.1030

26. Ferrero E, Lo Buono N, Morone S, Parrotta R, Mancini C, Brusco A, et al. Human canonical CD157/Bst1 is an alternatively spliced isoform masking a previously unidentified primate-specific exon included in a novel transcript. Sci Rep (2017) 7(1):15923. doi: 10.1038/s41598-017-16184-w

27. Higashida H. Somato-axodendritic release of oxytocin into the brain due to calcium amplification is essential for social memory. J Physiol Sci (2016) 66:275-82. doi: 10.1007/s12576-015-0425-0

28. Higashida H, Yokoyama S, Kikuchi M, Munesue T. CD38 and its role in oxytocin secretion and social behavior. Horm Behav (2012) 61:351-8. doi: 10.1016/j.yhbeh.2011.12.011

29. Jin D, Liu H-X, Hirai H, Torashima T, Nagai T, Lopatina O, et al. CD38 is critical for social behaviour by regulating oxytocin secretion. Nature (2007) 446:41-5. doi: 10.1038/nature05526

30. Tao R, Sun H-Y, Lau C-P, Tse H-F, Lee H-C, Li G-R. Cyclic ADP ribose is a novel regulator of intracellular $\mathrm{Ca} 2+$ oscillations in human bone marrow mesenchymal stem cells. J Cell Mol Med (2011) 15:2684-96. doi: 10.1111/ j.1582-4934.2011.01263.x

31. Lopatina O, Yoshihara T, Nishimura T, Zhong J, Akther S, Fakhrul AAKM, et al. Anxiety- and depression-like behavior in mice lacking the CD157/ BST1 gene, a risk factor for Parkinson's disease. Front Behav Neurosci (2014) 8:133. doi: 10.3389/fnbeh.2014.00133

32. Lopatina OL, Furuhara K, Ishihara K, Salmina AB, Higashida H. Communication Impairment in Ultrasonic Vocal Repertoire during the Suckling Period of Cd157 Knockout Mice: Transient Improvement by Oxytocin. Front Neurosci (2017) 11:266. doi: 10.3389/fnins.2017.00266

33. Lo Buono N. CD157 at the intersection between leukocyte trafficking and epithelial ovarian cancer invasion. Front Biosci (Landmark Ed) (2014) 19:366. doi: 10.2741/4213

34. Lo Buono N, Parrotta R, Morone S, Bovino P, Nacci G, Ortolan E, et al. The CD157-Integrin Partnership Controls Transendothelial Migration and Adhesion of Human Monocytes. J Biol Chem (2011) 286:18681-91. doi: $10.1074 /$ jbc.M111.227876

35. Shimaoka Y, Attrep JF, Hirano T, Ishihara K, Suzuki R, Toyosaki T, et al. Nurse-like cells from bone marrow and synovium of patients with rheumatoid arthritis promote survival and enhance function of human B cells. J Clin Invest (1998) 102:606-18. doi: 10.1172/JCI3162

36. Chung SJ, Jung Y, Hong M, Kim MJ, You S, Kim YJ, et al. Alzheimer's disease and Parkinson's disease genome-wide association study top hits and risk of Parkinson's disease in Korean population. Neurobiol Aging (2013) 34:2695.e1-2695.e7. doi: 10.1016/j.neurobiolaging.2013.05.022

37. Chang X-L, Mao X-Y, Li H-H, Zhang J-H, Li N-N, Burgunder J-M, et al. Association of GWAS loci with PD in China. Am J Med Genet B Neuropsychiatr Genet (2011) 156:334-9. doi: 10.1002/ajmg.b.31167

38. Chen M-L, Lin C-H, Lee M-J, Wu R-M. BST1 rs11724635 interacts with environmental factors to increase the risk of Parkinson's disease in a Taiwanese population. Parkinsonism Relat Disord (2014) 20:280-3. doi: 10.1016/j.parkreldis.2013.11.009

39. Liu J, Xiao Q, Wang Y, Xu Z-M, Wang Y, Yang Q, et al. Analysis of genomewide association study-linked loci in Parkinson's disease of Mainland China: GWAS-Linked PD Loci in Mainland China. Mov Disord (2013) 28:1892-5. doi: $10.1002 / \mathrm{mds} .25599$

40. Miyake Y, Tanaka K, Fukushima W, Kiyohara C, Sasaki S, Tsuboi Y, et al. Lack of association between BST1 polymorphisms and sporadic Parkinson's disease in a Japanese population. J Neurol Sci (2012) 323:162-6. doi: 10.1016/ j.jns.2012.09.008

41. Saad M, Lesage S, Saint-Pierre A, Corvol J-C, Zelenika D, Lambert J-C, et al. Genome-wide association study confirms BST1 and suggests a locus on $12 \mathrm{q} 24$ as the risk loci for Parkinson's disease in the European population. Hum Mol Genet (2011) 20:615-27. doi: 10.1093/hmg/ddq497

42. Satake W, Nakabayashi Y, Mizuta I, Hirota Y, Ito C, Kubo M, et al. Genomewide association study identifies common variants at four loci as genetic risk factors for Parkinson's disease. Nat Genet (2009) 41:1303-7. doi: 10.1038/ ng. 485

43. Sharma M, Ioannidis JPA, Aasly JO, Annesi G, Brice A, Van Broeckhoven C, et al. Large-scale replication and heterogeneity in Parkinson disease genetic loci. Neurology (2012) 79:659-67. doi: 10.1212/WNL.0b013e318264e353 
44. Simón-Sánchez J, van Hilten JJ, van de Warrenburg B, Post B, Berendse HW, Arepalli S, et al. Genome-wide association study confirms extant PD risk loci among the Dutch. Eur J Hum Genet (2011) 19:655-61. doi: 10.1038/ ejhg.2010.254

45. Tan E-K, Kwok H-K, Tan LC, Zhao W-T, Prakash KM, Au W-L, et al. Analysis of GWAS-linked loci in Parkinson disease reaffirms PARK16 as a susceptibility locus. Neurology (2010) 75:508-12. doi: 10.1212/WNL. 0b013e3181eccfcd

46. Wang C, Cai Y, Zheng Z, Tang B-S, Xu Y, Wang T, et al. Penetrance of LRRK2 G2385R and R1628P is modified by common PD-associated genetic variants. Parkinsonism Relat Disord (2012) 18:958-63. doi: 10.1016/ j.parkreldis.2012.05.003

47. Zhu L, Luo X, Zhou Y, Li F, Yang Y, Ren Y, et al. Lack of association between three single nucleotide polymorphisms in the PARK9, PARK15, and BST1 genes and Parkinson's disease in the northern Han Chinese population. Chin Med J (2012) 125:588-92. doi: 10.1016/S1353-8020(11)70766-0

48. Zimprich A. Genetics of Parkinson's disease and essential tremor. Curr Opin Neurol (2011) 24:318-23. doi: 10.1097/WCO.0b013e3283484b87

49. Yilmaz ÖH, Katajisto P, Lamming DW, Gültekin Y, Bauer-Rowe KE, Sengupta S, et al. mTORC1 in the Paneth cell niche couples intestinal stem-cell function to calorie intake. Nature (2012) 486:490-5. doi: 10.1038/ nature 11163

50. Wu N, Li Z, Su Y. The association between oxytocin receptor gene polymorphism (OXTR) and trait empathy. J Affect Disord (2012) 138:46872. doi: 10.1016/j.jad.2012.01.009

51. Ortolan E, Augeri S, Fissolo G, Musso I, Funaro A. CD157: From immunoregulatory protein to potential therapeutic target. Immunol Lett (2019) 205:59-64. doi: 10.1016/j.imlet.2018.06.007

52. Malinovskaya NA, Salmina AB, Prokopenko SV, Morgun AV, Kuvacheva $\mathrm{NV}, \mathrm{Yu} \mathrm{AP}$, et al. The coexpression of CD157/CD11b/CD18 in an experimental model of Parkinson's disease. Neurochem J (2015) 9:279-83. doi: 10.1134/S181971241504011X

53. Choucair-Jaafar N, Laporte V, Levy R, Poindron P, Lombard Y, Gies J-P. Complement receptor $3(\mathrm{CD} 11 \mathrm{~b} / \mathrm{CD} 18)$ is implicated in the elimination of $\beta$-amyloid peptides: CR3 and $\beta$-amyloid peptides phagocytosis. Fundam Clin Pharmacol (2011) 25:115-22. doi: 10.1111/j.1472-8206.2010.00811.x

54. Roy A, Fung YK, Liu X, Pahan K. Up-regulation of Microglial CD11b Expression by Nitric Oxide. J Biol Chem (2006) 281:14971-80. doi: 10.1074/ jbc.M600236200

55. Zhou H, Liao J, Aloor J, Nie H, Wilson BC, Fessler MB, et al. CD11b/CD18 (Mac-1) Is a Novel Surface Receptor for Extracellular Double-Stranded RNA To Mediate Cellular Inflammatory Responses. J Immunol (2013) 190:11525. doi: $10.4049 /$ jimmunol.1202136

56. Lavagno L, Ferrero E, Ortolan E, Malavasi F, Funaro A. CD157 is part of a supramolecular complex with $\mathrm{CD} 11 \mathrm{~b} / \mathrm{CD} 18$ on the human neutrophil cell surface. J Biol Regul Homeost Agents (2007) 21:5-11.

57. Salmina AB, Komleva YK, Lopatina OL, Kuvacheva NV, Gorina YV, Panina YA, et al. Astroglial control of neuroinflammation: TLR3-mediated dsRNAsensing pathways are in the focus. Rev Neurosci (2015) 26(2):143-59. doi: 10.1515/revneuro-2014-0052

58. Zhang D, Hu X, Qian L, Chen S-H, Zhou H, Wilson B, et al. Microglial MAC1 receptor and PI3K are essential in mediating $\beta$-amyloid peptide-induced microglial activation and subsequent neurotoxicity. J Neuroinflammation (2011) 8:3. doi: 10.1186/1742-2094-8-3

59. Field R, Campion S, Warren C, Murray C, Cunningham C. Systemic challenge with the TLR3 agonist poly I:C induces amplified IFN $\alpha / \beta$ and IL-1 $\beta$ responses in the diseased brain and exacerbates chronic neurodegeneration. Brain Behav Immun (2010) 24:996-1007. doi: 10.1016/ j.bbi.2010.04.004

60. Noda M, Ifuku M, MdS H, Katafuchi T. Glial Activation and Expression of the Serotonin Transporter in Chronic Fatigue Syndrome. Front Psychiatry (2018) 9:589. doi: 10.3389/fpsyt.2018.00589

61. Ifuku M, Hossain SM, Noda M, Katafuchi T. Induction of interleukin- $1 \beta$ by activated microglia is a prerequisite for immunologically induced fatigue. Eur J Neurosci (2014) 40:3253-63. doi: 10.1111/ejn.12668

62. Maeda T, Inagaki M, Fujita Y, Kimoto T, Tanabe-Fujimura C, Zou K, et al. ATP increases the migration of microglia across the brain endothelial cell monolayer. Biosci Rep (2016) 36(2):e00318. doi: 10.1042/BSR20160054
63. Malinovskaya NA, Komleva YK, Salmin VV, Morgun AV, Shuvaev AN, Panina YA, et al. Endothelial Progenitor Cells Physiology and Metabolic Plasticity in Brain Angiogenesis and Blood-Brain Barrier Modeling. Front Physiol (2016) 7:599. doi: 10.3389/fphys.2016.00599

64. Ungvari Z, Tarantini S, Kiss T, Wren JD, Giles CB, Griffin CT, et al. Endothelial dysfunction and angiogenesis impairment in the ageing vasculature. Nat Rev Cardiol (2018) 15:555-65. doi: 10.1038/s41569-0180030-z

65. Cunningham C, Campion S, Lunnon K, Murray CL, Woods JFC, Deacon RMJ, et al. Systemic Inflammation Induces Acute Behavioral and Cognitive Changes and Accelerates Neurodegenerative Disease. Biol Psychiatry (2009) 65:304-12. doi: 10.1016/j.biopsych.2008.07.024

66. Haida $\mathrm{O}, \mathrm{Al}$ Sagheer $\mathrm{T}$, Balbous $\mathrm{A}$, Francheteau M, Matas E, Soria F, et al. Sex-dependent behavioral deficits and neuropathology in a maternal immune activation model of autism. Trans Psychiatry (2019) 9(124):1-12. doi: 10.1038/s41398-019-0457-y

67. Haddad FL, Patel SV, Schmid S. Maternal Immune Activation by Poly I:C as a preclinical Model for Neurodevelopmental Disorders: A focus on Autism and Schizophrenia. Neurosci Biobehav Rev (2020) 113:546-67. doi: 10.1016/ j.neubiorev.2020.04.012

68. Horváth G, Otrokocsi L, Bekő K, Baranyi M, Kittel Á, Antonio FritzRuenes $\mathrm{P}$, et al. $\mathrm{P} 2 \mathrm{X} 7$ receptors drive poly(I:C) induced autism-like behavior in mice. J Neurosci (2019) 39(13):2542-61. doi: 10.1523/ JNEUROSCI.1895-18.2019

69. Ceroni F, Sagar A, Simpson NH, Gawthrope AJT, Newbury DF, Pinto D, et al. A Deletion Involving $C D 38$ and BST 1 Results in a Fusion Transcript in a Patient With Autism and Asthma: CD38/BST1 deletion with autism and asthma. Autism Res (2014) 7:254-63. doi: 10.1002/aur.1365

70. Yokoyama S, Al Mahmuda N, Munesue T, Hayashi K, Yagi K, Yamagishi M, et al. Association Study between the CD157/BST1 Gene and Autism Spectrum Disorders in a Japanese Population. Brain Sci (2015) 5:188-200. doi: 10.3390/brainsci5020188

71. DiStefano C, Shih W, Kaiser A, Landa R, Kasari C. Communication growth in minimally verbal children with ASD: The importance of interaction: Communication in minimally verbal children. Autism Res (2016) 9:1093102. doi: 10.1002/aur.1594

72. Eigsti I-M, de Marchena AB, Schuh JM, Kelley E. Language acquisition in autism spectrum disorders: A developmental review. Res Autism Spectr Disord (2011) 5:681-91. doi: 10.1016/j.rasd.2010.09.001

73. Gaub S, Fisher SE, Ehret G. Ultrasonic vocalizations of adult male Foxp2 -mutant mice: behavioral contexts of arousal and emotion: Ultrasonic vocalizations of Foxp2 mutant mice. Genes Brain Behav (2016) 15:243-59. doi: $10.1111 / \mathrm{gbb} .12274$

74. Kim H, Son J, Yoo H, Kim H, Oh J, Han D, et al. Effects of the Female Estrous Cycle on the Sexual Behaviors and Ultrasonic Vocalizations of Male C57BL/6 and Autistic BTBR T+ tf/J Mice. Exp Neurobiol (2016) 25:156-62. doi: $10.5607 / \mathrm{en} .2016 .25 .4 .156$

75. Matsumoto YK, Okanoya K. Phase-Specific Vocalizations of Male Mice at the Initial Encounter during the Courtship Sequence. PloS One (2016) 11: e0147102. doi: 10.1371/journal.pone.0147102

76. Wöhr M, Schwarting RKW. Ultrasonic Communication in Rats: Can Playback of $50-\mathrm{kHz}$ Calls Induce Approach Behavior? PloS One (2007) 2: e1365. doi: 10.1371/journal.pone.0001365

77. Lahvis GP, Alleva E, Scattoni ML. Translating mouse vocalizations: prosody and frequency modulation1. Genes Brain Behav (2011) 10:4-16. doi: 10.1111/j.1601-183X.2010.00603.x

78. Scattoni ML, Gandhy SU, Ricceri L, Crawley JN. Unusual Repertoire of Vocalizations in the BTBR T+tf/J Mouse Model of Autism. PloS One (2008) 3:e3067. doi: 10.1371/journal.pone.0003067

79. Scattoni ML, Crawley J, Ricceri L. Ultrasonic vocalizations: A tool for behavioural phenotyping of mouse models of neurodevelopmental disorders. Neurosci Biobehav Rev (2009) 33:508-15. doi: 10.1016/j. neubiorev.2008.08.003

80. Dichter GS, Brunelli SA, Hofer MA. Elevated plus-maze behavior in adult offspring of selectively bred rats. Physiol Behav (1996) 60:299-304. doi: 10.1016/0031-9384(95)02222-8

81. Barbeau EB, Lewis JD, Doyon J, Benali H, Zeffiro TA, Mottron L. A greater involvement of posterior brain areas in interhemispheric transfer in autism: 
fMRI, DWI and behavioral evidences. NeuroImage: Clin (2015) 8:267-80. doi: 10.1016/j.nicl.2015.04.019

82. Arunachalam S, Luyster RJ. The integrity of lexical acquisition mechanisms in autism spectrum disorders: A research review: lexical acquisition in ASD. Autism Res (2016) 9:810-28. doi: 10.1002/aur.1590

83. Hamilton SM, Spencer CM, Harrison WR, Yuva-Paylor LA, Graham DF, Daza RAM, et al. Multiple autism-like behaviors in a novel transgenic mouse model. Behav Brain Res (2011) 218:29-41. doi: 10.1016/j.bbr.2010.11.026

84. Homberg JR, Kyzar EJ, Nguyen M, Norton WH, Pittman J, Poudel MK, et al. Understanding autism and other neurodevelopmental disorders through experimental translational neurobehavioral models. Neurosci Biobehav Rev (2016) 65:292-312. doi: 10.1016/j.neubiorev.2016.03.013

85. Nawijn L, van Zuiden M, Koch SBJ, Frijling JL, Veltman DJ, Olff M. Intranasal oxytocin enhances neural processing of monetary reward and loss in posttraumatic stress disorder and traumatized controls. Psychoneuroendocrinology (2016) 66:228-37. doi: 10.1016/j.psyneuen.2016.01.020

86. Kemp AH, Quintana DS, Kuhnert R-L, Griffiths K, Hickie IB, Guastella AJ. Oxytocin Increases Heart Rate Variability in Humans at Rest: Implications for Social Approach-Related Motivation and Capacity for Social Engagement. PloS One (2012) 7:e44014. doi: 10.1371/journal.pone.0044014

87. Gordon I, Vander Wyk BC, Bennett RH, Cordeaux C, Lucas MV, Eilbott JA, et al. Oxytocin enhances brain function in children with autism. Proc Natl Acad Sci (2013) 110:20953-8. doi: 10.1073/pnas.1312857110

88. Mo W, Liu J, Zhang Z, Yu H, Yang A, Qu F, et al. Hu F. A study of single nucleotide polymorphisms in CD157, AIM2 and JARID2 genes in Han Chinese children with autism spectrum disorder. Nord J Psychiatry (2018) 72:179-83. doi: 10.1080/08039488.2017.1410570

89. Chong A, Malavasi F, Israel S, Khor CC, Yap VB, Monakhov M, et al. ADP ribosyl-cyclases (CD38 / CD157), social skills and friendship. Psychoneuroendocrinology (2017) 78:185-92. doi: 10.1016/j.psyneuen.2017. 01.011

90. Kasai S, Yoshihara T, Lopatina O, Ishihara K, Higashida H. Selegiline Ameliorates Depression-Like Behavior in Mice Lacking the CD157/BST1 Gene, a Risk Factor for Parkinson's Disease. Front Behav Neurosci (2017) 11:75. doi: 10.3389/fnbeh.2017.00075

91. Mizuno A, Cherepanov S, Kikuchi Y, Fakhrul A, Akther S, Deguchi K, et al. Lipo-oxytocin-1, a Novel Oxytocin Analog Conjugated with Two Palmitoyl Groups, Has Long-Lasting Effects on Anxiety-Related Behavior and Social Avoidance in CD157 Knockout Mice. Brain Sci (2015) 5:3-13. doi: 10.3390/ brainsci5010003

92. Harding AJ, Stimson E, Henderson JM, Halliday GM. Clinical correlates of selective pathology in the amygdala of patients with Parkinson's disease. Brain (2002) 125:2431-45. doi: 10.1093/brain/awf251

93. Surdhar I, Gee M, Bouchard T, Coupland N, Malykhin N, Camicioli R. Intact limbic-prefrontal connections and reduced amygdala volumes in Parkinson's disease with mild depressive symptoms. Parkinsonism Relat Disord (2012) 18:809-13. doi: 10.1016/j.parkreldis.2012.03.008
94. Komleva Y, Kuvacheva NV, Malinocskaya NA, Gorina Y, Lopatina OL, Teplyashina EA, et al. Regenerative potential of the brain: Composition and forming of regulatory microenvironment in neurogenic niches. Hum Physiol (2016) 42:865-73. doi: 10.1134/S0362119716080077

95. Pozhilenkova EA, Lopatina OL, Komleva YK, Salmin VV, Salmina AB. Blood-brain barrier-supported neurogenesis in healthy and diseased brain. Rev Neurosci (2017) 28(4):397-415. doi: 10.1515/revneuro-2016-0071

96. A Menini ed. The neurobiology of olfaction. Boca Raton, FL: CRC Press/ Taylor \& Francis (2010).

97. Salmina AB, Komleva YK, Lopatina OL, Gorina YV, Malinovskaya NA, Pozhilenkova EA, et al. CD38 and CD157 Expression: Glial Control of Neurodegeneration and Neuroinflammation. Messenger (2014) 3:78-85. doi: 10.1166/msr.2014.1037

98. Li J, Luo J, Liu L, Fu H, Tang L. The association between CD157/BST1 polymorphisms and the susceptibility of Parkinson's disease: a metaanalysis. Neuropsychiatr Dis Treat (2019) 15:1089-102. doi: 10.2147/ NDT.S190935

99. Katoh M, Katoh M. CD157 and CD200 at the crossroads of endothelial remodeling and immune regulation. Stem Cell Invest (2019) 6:10-0. doi: $10.21037 /$ sci.2019.04.01

100. Lin R, Cai J, Nathan C, Wei X, Schleidt S, Rosenwasser R, et al. Neurogenesis is enhanced by stroke in multiple new stem cell niches along the ventricular system at sites of high BBB permeability. Neurobiol Dis (2015) 74:229-39. doi: 10.1016/j.nbd.2014.11.016

101. Wakabayashi T, Naito H, Suehiro J, Lin Y, Kawaji H, Iba T, et al. CD157 Marks Tissue-Resident Endothelial Stem Cells with Homeostatic and Regenerative Properties. Cell Stem Cell (2018) 22:384-97. doi: 10.1016/ j.stem.2018.01.010

102. Takakura N. Discovery of a Vascular Endothelial Stem Cell (VESC) Population Required for Vascular Regeneration and Tissue Maintenance. Circ J (2018) 83:12-7. doi: 10.1253/circj.CJ-18-1180

103. Osipova ED, Komleva YK, Morgun AV, Lopatina OL, Panina YA, Olovyannikova $\mathrm{R}$, et al. Designing in vitro Blood-Brain Barrier Models Reproducing Alterations in Brain Aging. Front Aging Neurosci (2018) 10:234. doi: 10.3389/fnagi.2018.00234

Conflict of Interest: The authors declare that the research was conducted in the absence of any commercial or financial relationships that could be construed as a potential conflict of interest.

Copyright $\odot 2020$ Lopatina, Komleva, Malinovskaya, Panina, Morgun and Salmina. This is an open-access article distributed under the terms of the Creative Commons Attribution License (CC BY). The use, distribution or reproduction in other forums is permitted, provided the original author(s) and the copyright owner(s) are credited and that the original publication in this journal is cited, in accordance with accepted academic practice. No use, distribution or reproduction is permitted which does not comply with these terms. 